\title{
Seismic Resistance and Damping Model Test and Numerical Simulation of Highway Tunnel
}

\author{
Sheng Bao Zheng ${ }^{1, *}$ and Shu Ping Jiang ${ }^{2}$ \\ ${ }^{1}$ Chongqing Jiaotong University, Chongqing, 400074, China; ${ }^{2}$ Chongqing Communications Research and Design Insti- \\ tute, Chongqing, 400074, China
}

\begin{abstract}
In this paper,we established a seismic resistance and damping model to study the effects of tunnel under seismic waves.We took the entrance of Galongla Tunnel as prototype, drafted the similarity relationships of the model.Damping layers and the measuring points of shaking table model have been arranged. We carried out loading test of the shaking table. Compared with the results of finite element analysis, the damping ratio has been defined to analyze the dynamic characteristics and the effect of damping layers. We come to conclusion that damping layers have some effects and surrounding rocks can filter high frequency components of the seismic waves.
\end{abstract}

Keywords: Damping layer, FE model, damping ratio, model test. seismic wave, tunnel.

\section{INTRODUCTION}

Investigations of earthquake disaster, increasingly suggest that strong earthquakes can damage not only surface structures but also the underground tunnel, for instance the Kobe earthquake in 1995 caused the destruction of numerous subway structures. Tunnels design for high intensity seismic regions must consider seismic resistance and damping performance. Currently, the seismic resistance and damping performance measures of highway tunnels are identified as: (1) Strengthening the intensity of the structure itself for earthquake resistance and damage control within an affordable range. (2) Applying appropriate measures to alter the properties of structures to adapt and even improve the capability of the building's performance under the influence of vibration. Specific measures such as grouting of surrounding rocks,adding seismic joints and damping layers, and utilizing fiber reinforced concrete lining are also carried out to minimize the influence of vibration on the structure [1-4].

The Galongla Tunnel is a two-lane tunnel, 3.310 kilometers in length, located in a complex geologic site with intensive seismicity in the mid-Tibet and Himalaya seismic zone of the southern Tibetan plateau.there are 9 geological fractures of various size surrounding the tunnel, which can induce an 8.0 magnitude earthquake. The Galongla tunnel was utilized as a prototype for the seismic resistance and damping performance model test. The results of the dynamic load experiment produced from the test were analyzed and compared with the results of finite element analysis.Finally, the conclusion was reached that damping layers had some effects on tunnel vibration.

\section{TEST DESIGN}

The tunnel entrance is considered as the most critical part of tunnel seismic fortification $[5,6]$ during and earthquake.
In the test, dynamic analysis is only carried out at the entrance part of tunnel and the longitudinal range of the model is $100 \mathrm{~m}$ longitudinal at the entrance of Galongla tunnel. According to the reference [7], the dynamic calculation tends to be stable and the influence of lateral boundary can be ignored when the proportion between the foundation plane and the dimension and structure plane is greater than 5. The transverse range of Galongla tunnel is $45 \mathrm{~m}$ from the central line to each side of the tunnel. The maximum buried depth of tunnel is $48 \mathrm{~m}$ while the inverted arch is $28 \mathrm{~m}$ and the variation range of height is $84 \mathrm{~m}$, as presented in Fig. (1). The model test is completed at the Dynamics Laboratory of Chongqing Communications Research \& Design Institute and the bidirectional electro-hydraulic seismic simulation vibration platform with 4 degrees of freedom, made by SCHENCK, Germany, which is used in the vibration platform model test. The test model was made up by a foam plate model box, surrounded by rocks and tunnel lining etc. In the model, a similar material of surrounding rock under the tunnel floor is cast-in-site while the one above the floor is prefabricated.The lining is completed after the prefabrication of similar material.

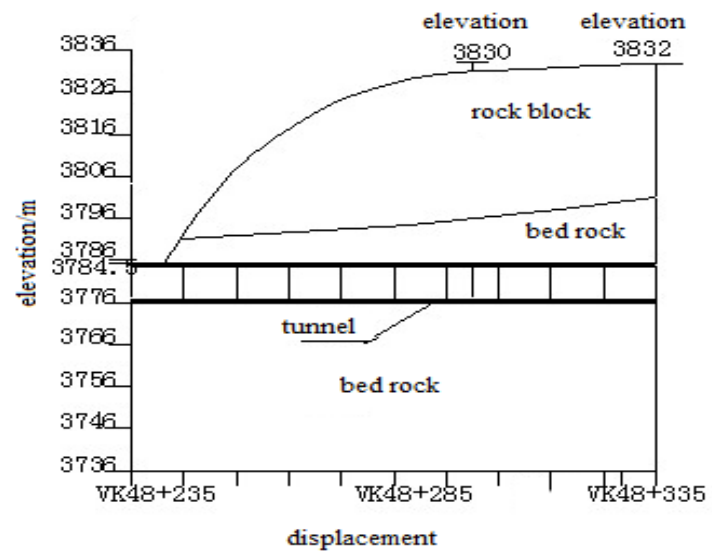

Fig. (1). Elevation layout of tunnel entrance segment. 


\subsection{The Test of Similar Coefficient and Material}

Considering the dimensions of the shocking table and the model box, as well as the influence of economy, a scaled test was performed with a geometric similarity ratio $1 / 40$. The model size is $3.010 \mathrm{~m}$ in length, $2.710 \mathrm{~m}$ in width and $2.450 \mathrm{~m}$ in height. The seismic deformation joints or construction joints were set on the tunnel lining every $0.250 \mathrm{~m}$. The similarity of the model to the actual tunnel is shown in Table 1.

Table 1. Dynamic similar coefficient in shaking model test.

\begin{tabular}{|c|c|c|}
\hline $\begin{array}{c}\text { Physical } \\
\text { quantities }\end{array}$ & $\begin{array}{c}\text { Symbols and } \\
\text { expressions }\end{array}$ & $\begin{array}{c}\text { Similar } \\
\text { relationship }\end{array}$ \\
\hline \hline geometric dimension & $\mathrm{CL}$ & $1 / 40$ \\
\hline density & $\mathrm{C} \rho$ & $1 / 1$ \\
\hline Modulus of elasticity & $\mathrm{CE}$ & $1 / 20$ \\
\hline Poisson's ratio & dimensionless & $1 / 1$ \\
\hline $\begin{array}{c}\text { Angle of internal } \\
\text { friction }\end{array}$ & dimensionless & $1 / 1$ \\
\hline time & $\mathrm{C}_{\mathrm{t}}=\mathrm{C}_{\mathrm{L}}\left(\mathrm{C}_{\mathrm{E}} / \mathrm{C}_{\rho}\right)^{-1 / 2}$ & $1 / 8.944$ \\
\hline acceleration & $\mathrm{C}_{\mathrm{a}}=\mathrm{C}_{\mathrm{L}}^{-1}\left(\mathrm{C}_{\mathrm{E}} / \mathrm{C}_{\rho}\right)$ & $1 / 0.5$ \\
\hline displacement & $\mathrm{C}_{\mathrm{u}}=\mathrm{C}_{\mathrm{L}}$ & $1 / 40$ \\
\hline velocity & $\mathrm{C}_{\mathrm{v}}=\left(\mathrm{C}_{\mathrm{E}} / \mathrm{C}_{\rho}\right)^{1 / 2}$ & $1 / 4.472$ \\
\hline frequency & $\mathrm{C}_{\mathrm{f}}=\mathrm{C}_{\mathrm{L}}^{-1}\left(\mathrm{C}_{\mathrm{E}} / \mathrm{C}_{\rho}\right)^{1 / 2}$ & $1 / 0.112$ \\
\hline
\end{tabular}

The physical and mechanical parameters of the surrounding rocks of the Galongla tunnel entrance section are Grade $\mathrm{V}$. The surrounding rocks of the tunnel consist of $\mathrm{BaSO}_{4}$ powder, zinc oxide, gypsum, quartz sand and glycerol, providing a very specific geological condition.Likewise, the tunnel's linings are composed of gypsum and water in specific proportions. Anchors and lining steel were simulated by galvanized steel wires. The materials of the tunnel's surrounding rocks are shown in Table 2.

Table 2. Material compounding ratio of surrounding soil and lining.

\begin{tabular}{|c|c|c|c|c|c|c|}
\hline $\begin{array}{c}\text { Material } \\
\text { number }\end{array}$ & Gypsum & BaSO $_{4}$ & $\begin{array}{c}\text { Quartz } \\
\text { sand }\end{array}$ & $\begin{array}{c}\text { Zinc } \\
\text { oxide }\end{array}$ & Glycerin & Water \\
\hline \hline $\begin{array}{c}\text { surrounding } \\
\text { rock V }\end{array}$ & $3-6$ & $63-70$ & $14-20$ & $6-0$ & $2-3$ & $15-1$ \\
\hline $\begin{array}{c}\text { The second } \\
\text { lining }\end{array}$ & 1 & - & - & - & - & 0.7 \\
\hline
\end{tabular}

\subsection{Boundary Condition}

To reduce friction between the boundary and the rocks and to avoid slippage between the geotechnical model and the steel plate at the bottom of the box during excitation, polystyrene foam plates with a $0.225 \mathrm{~m}$ thickness were set up around the box, and a layer of crushed stone was bonded to the bottom of the box.

\subsection{Establishing The Physical Model}

Both cast-in-place and precast block methods were utilized in duplicating the surrounding rocks in the model. Materials similar to the surrounding rock need to be prepared proportionately and poured into molds for each layer. These precast blocks need to be maintained properly in the molds for three to five days, depending on weather conditions. Next, they must be removed from the molds and cured for 10 days. Cast-in-place sample models have three different sizes: $\ominus$ a $500 \times 200 \times 80 \mathrm{~mm}$ model, which filled in the area that was under the tunnel lining or $35 \mathrm{~mm}$ away around the tunnel; $\ominus$ a $250 \times 200 \times 80 \mathrm{~mm}$ model and a $62.5 \times 200 \times 80 \mathrm{~mm}$ model, which filled in the area above the tunnel. A mold, with a thickness of $50 \mathrm{~mm}$, was utilized for casting the surrounding rocks, as shown in Fig. (2). The entire area (700 $\mathrm{mm}$ away from the tunnel model and $80 \mathrm{~mm}$ beneath the ground) was filled with cast-in-place surrounding rock (shown in Fig. 3) models to facilitate the installation of anchor bolts and to make initial lining and simulation of the loose accumulation layer on the surface and weathered layer of the rock more accurate [5].

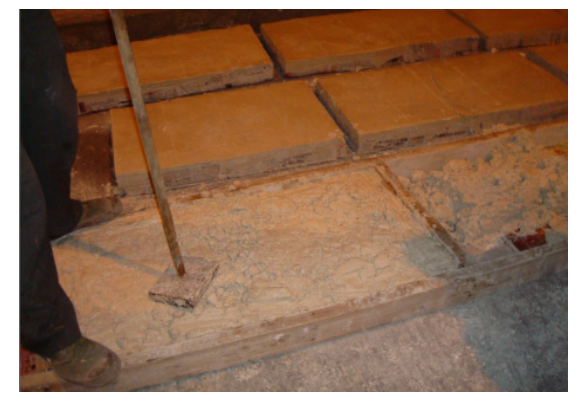

Fig. (2). Prefabrication of surrounding rocks.

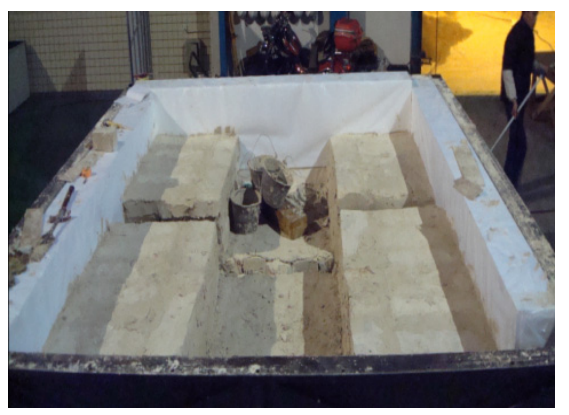

Fig. (3). Cast-in-place surrounding rock.

2) In accordance with similar theories, the lining of the tunnel model is $11.25 \mathrm{~mm}$ in thickness, and the length of each segment is $250 \mathrm{~mm}$. To simulate the pre-stressed concrete, we utilized plaster and a $\varphi 0.4 \mathrm{~mm}$ woven steel fabric to simulate the steel bar (Fig. 4). prior to molding, a layer of engine oil was painted on the interior walls of the mold. The prepared plaster liquid was then poured into the mold's grooves, and it demolded a half hour later. The strength of the lining was qualified after being maintained under normal temperature for seven days. How the lining was prefabricated and the mold itself are shown in Fig. (5). 


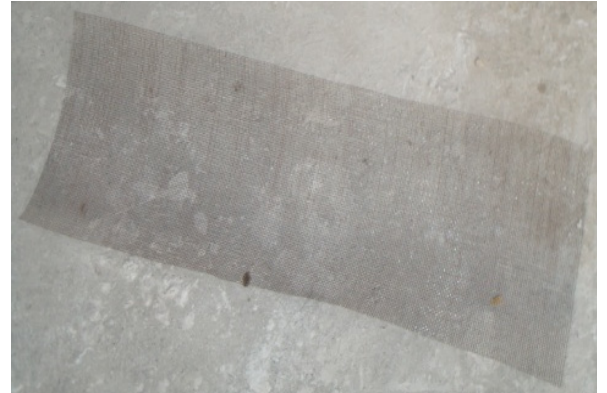

Fig. (4). Reinforcements in secondary lining.

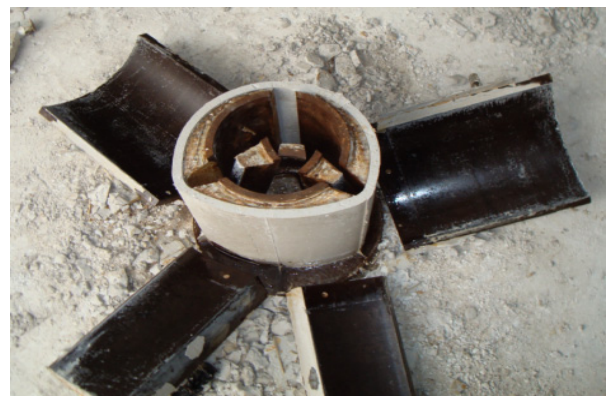

Fig. (5). Mold of secondary lining.

For the shocking table model test, $0.005 \mathrm{~m}$ thick damping layers were installed between the lining and surrounding rocks, using polyvinyl chloride polymer rubber material, as shown in Fig. (6). The spacing distance of seismic joint was $0.250 \mathrm{~m}$ and simulated with polyvinyl chloride polymer rubber with a thickness of $5 \mathrm{~mm}$.

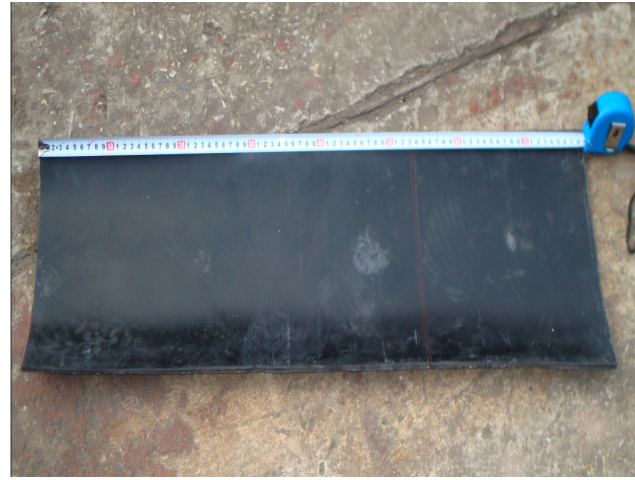

Fig. (6). Damping layer.

\subsection{Measuring Point Arrangement}

As shown in Fig. (7). Four main monitoring cross sections were identified as $\mathrm{A}-\mathrm{A}, \mathrm{B}-\mathrm{B}, \mathrm{C}-\mathrm{C}$ and $\mathrm{D}-\mathrm{D}$ and set in the middle of the second, fourth, fifth and tenth lining sections from the tunnel entrance, respectively. Aided monitoring cross sections were identified as $0-0,1-1,2-2$, $3-3$ and $4-4$ and set in the middle of the remaining lining sections. The other four monitoring cross sections were identified as I-I, II-II, III-III and IV-IV and set at the seismic joints of the lining. The transverse arrangement of the main monitoring sections are shown in Fig. (8), in which $\mathrm{P}^{\prime} \mathrm{A} \mathrm{G}^{\prime} \mathrm{G} \mathrm{D}$ represent the instruments to test displacement (P) 'acceleration (A)'velocity (G)'and strain (D) of this measuring point, respectively.

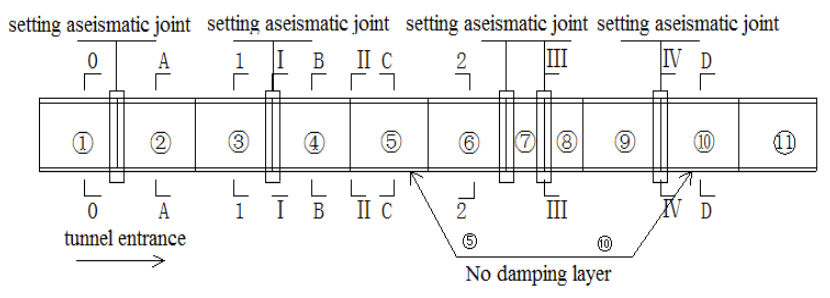

Fig. (7). Layout of monitoring section lining.
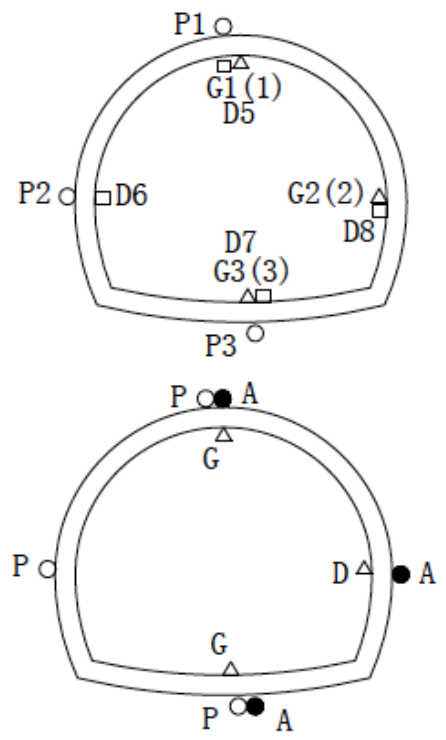

Fig. (8). Layout of measuring points.

\subsection{Loading Rule}

Due to the lack of in-situ measurements of seismic waves and the transmission patterns of waves, artificial seismic waves were used based on the acceleration spectrum, with exceeding probability as $63 \%, 10 \%, 5 \%$ and $2 \%$, respectively over 50 years. The time history of seismic wave curve and Fourier spectrum are presented in Fig. (9). The loading system is presented in Table $\mathbf{3}$.

\section{CACULATION MODEL}

\subsection{Calculation Zone and Mesh Generation}

In this article, the numerical calculation is limited by the model box, and the side length of mesh element was controlled within $3 \mathrm{~m}$ by adjusting the physical parameters of damping layer in the finite element model in order to determine the shock absorption layer. There is no damping layer if the physical parameters are placed into the surrounding rocks. The model grid of numerical calculation damping layers and seismic joints are shown by the following Fig. (10) [6-9].

\subsection{The Material Constitutive Model}

Surrounding rocks were simulated by solid elements with elastic-plastic incremental constitutive associations according to the Mohr-Coulomb yield criterion. Lining was simulated by shell elements and elastic constituents. [10,11]. 


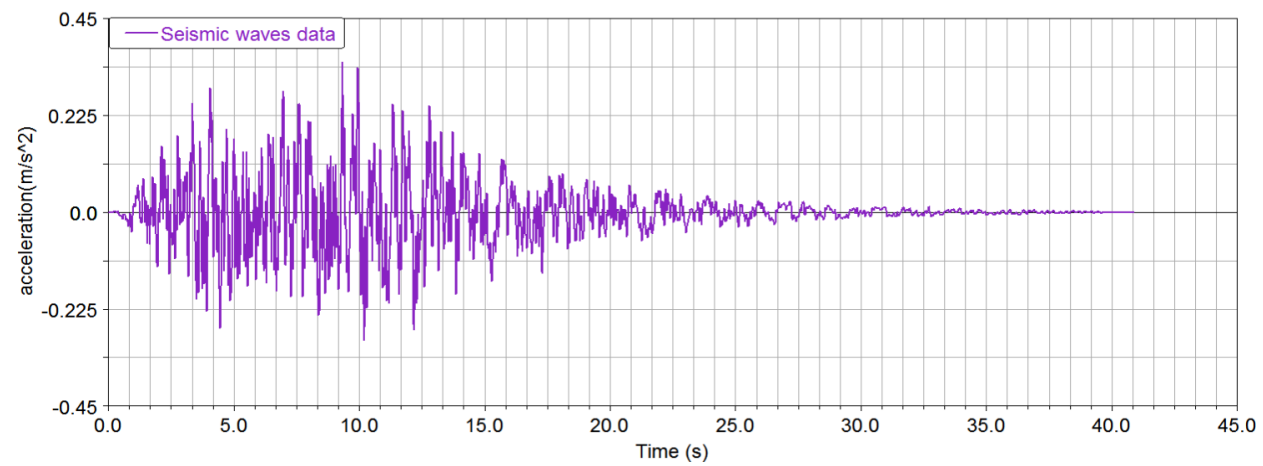

Fig. (9). Acceleration time history of seismic wave with exceedance probability of $10 \%$.

Table 3. Loading rule table in model test.

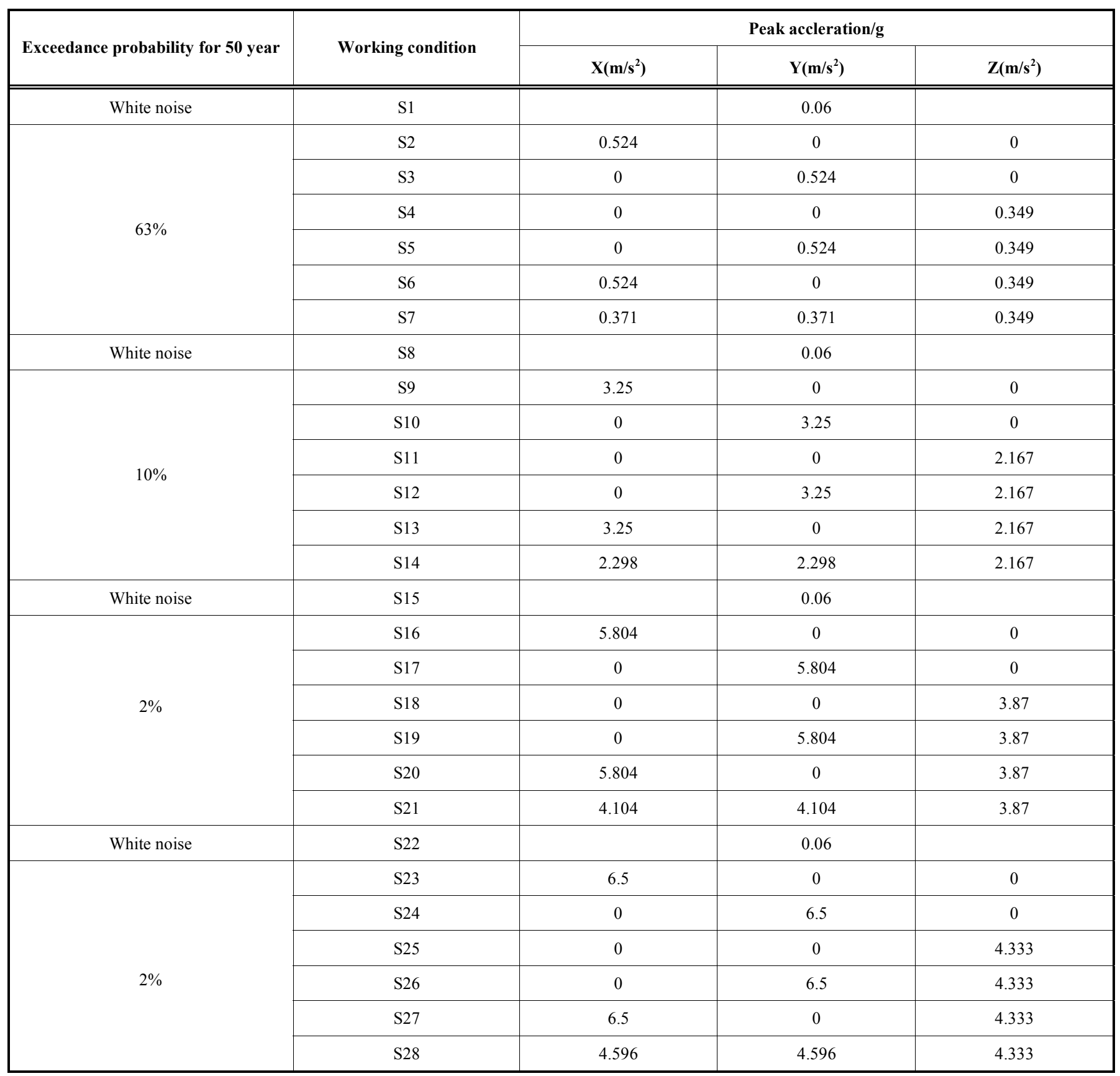




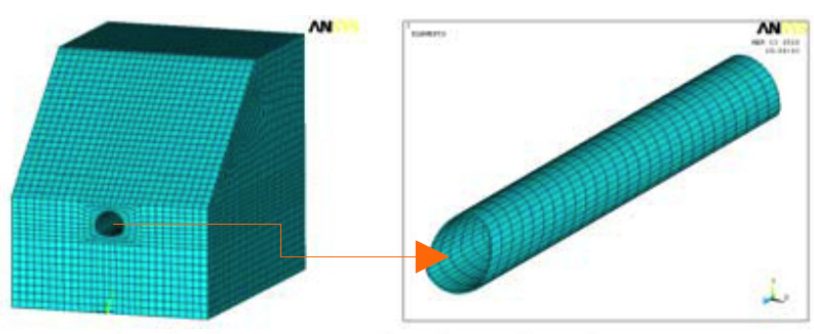

a) calculation zone b) damping layer

Fig. (10). Tunnel FE model.

\subsection{Test Parameter of Model}

Table 4. Test parameter used in model.

\begin{tabular}{|c|c|c|c|c|c|}
\hline Material type & $\begin{array}{c}E \\
(\mathbf{P a})\end{array}$ & $M$ & $\begin{array}{c}C \\
(\mathbf{P a})\end{array}$ & $\begin{array}{c}\Phi \\
(\operatorname{deg})\end{array}$ & $\begin{array}{c}\rho \\
\left(\mathrm{kg} / \mathrm{m}^{3}\right)\end{array}$ \\
\hline surrounding rock & $1.20 \mathrm{E}+09$ & 0.38 & $3.00 \mathrm{E}+05$ & 42 & 1800 \\
\hline lining & $3.35 \mathrm{E}+10$ & 0.2 & - & - & 2300 \\
\hline damping layer & $1.00 \mathrm{E}+06$ & 0.38 & - & - & 1000 \\
\hline
\end{tabular}

\subsection{Boundary Condition and Load Input}

Concentrated viscous-spring artificial boundary is utilized in the dynamic model and simulated by the mass spring element combination 14. Two planes in the Z Direction (vertical to the axis direction of tunnel) of tunnel entrance were set as viscous boundary, while the free face and the ZOY plane were defined as free boundary at the upper part of the tunnel, and fixed boundary at the bottom. The remaining planes of the model are set as viscous boundary except the upper and bottom plane.

Loading test method is shown in Table 4.

\section{THE DYNAMIC RESPONSE AND EFFECT FAC- TORS ANALYSIS OF THE TUNNEL}

\subsection{The Acceleration Response of The Soil}

During the test, resulting data from the sensors was often recorded and mixed with noise from the loading equipment. The low frequency noise causes the resulting data to deviate from the ordinates, and the high frequency noise significantly changes the recorded waveform. A filtering process was added so all data would simulate the real seismic response of the model. Efforts to study the dynamic property of the soil under the influence of seismic force are shown in Fig. (11), which includes the acceleration of time, history and frequency spectra of slope (measuring point A13); the ground surface (measuring point A14); and vibration table (measuring point A15) under the incidence of seismic waves with 50 years exceedance probability of $10 \%$.

The dynamic characteristics of surrounding rocks can be obtained from Fig. (11). The dominate frequency range of the surrounding rock and the basal seismic input is from 7.5 to $15 \mathrm{~Hz}$ and $7.5-20 \mathrm{~Hz}$, respectively. The frequency components of the Fourier spectrum increased in a range from 0 to $20 \mathrm{~Hz}$, after the value of $20 \mathrm{~Hz}$, decreased notably compared with the basal seismic waves input. The peak acceleration of the slope and the ground surface was three times higher than the basal incident seismic wave and slightly higher than the other slope.

Dynamic characteristics of soil body can be observed in Fig. (11):

1) predominant frequency range of soil is within $7.5-15 \mathrm{~Hz}$, predominant frequency of the seismic waves inputed into substrate is in the range of $17.5-20 \mathrm{~Hz}$.

2) Compared to the seismic waves inputed from the base, the Fourier spectrum components in $0-20 \mathrm{~Hz}$ range of soil increased and components above $20 \mathrm{~Hz}$ reduced significantly.

3) Peak acceleration at slope and ground surface is three times that of the seismic waves inputed into substrate.

4) Peak acceleration of the ground surface is slightly larger than the slope

The following conclusions can been drawn by the previous analysis:

1) No process resonance occurs in the physical model testing, the soil has significant amplification to lowfrequency components under $20 \mathrm{~Hz}$ and particular frequency components near predominant frequency of soil and filter wave to high frequency components above $20 \mathrm{~Hz}$.

2) Acceleration amplification factor increases along the bottom to the top of the slope.

The soil Fourier spectrum is displayed in Fig. (12), when seismic waves with different peak acceleration were loaded, in which the peak acceleration in case 1, case 2 and case 3 were $0.3494 \mathrm{~m} / \mathrm{s} 2,2.1666 \mathrm{~m} / \mathrm{s} 2,3.8695 \mathrm{~m} / \mathrm{s} 2$, respectively. It can be observed from Fig. (11) that with the increase of 


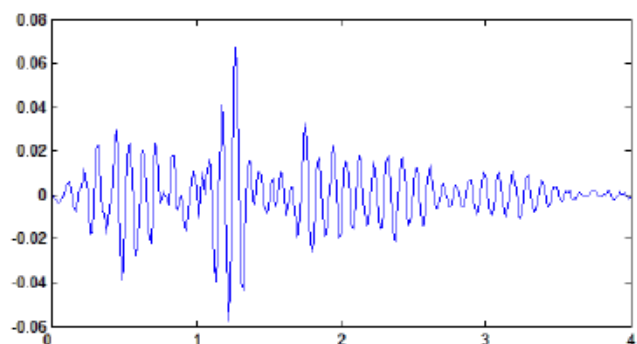

1) Acceleration Time History of A13 Measuring Point

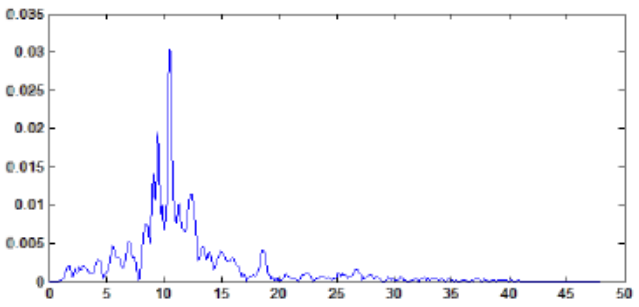

2) Frequency Spectra of A13 Measuring Point

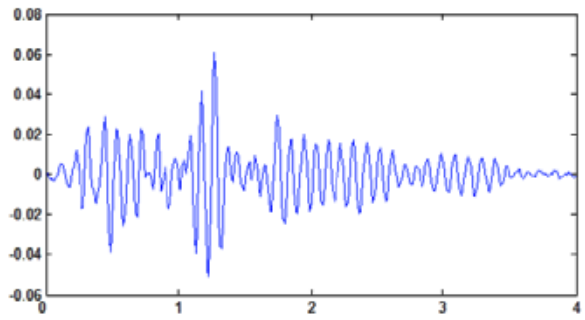

3) Acceleration Time History of A14 Measuring Point

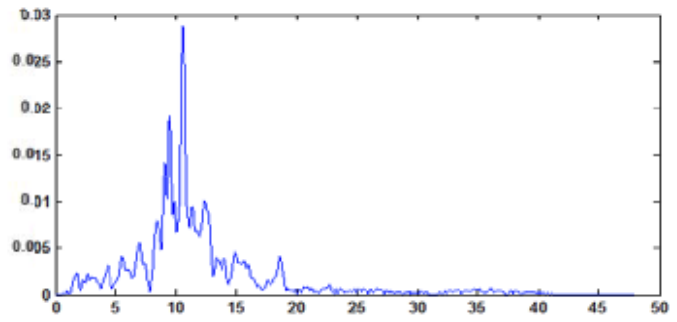

4) Frequency Spectra A14 Measuring Point

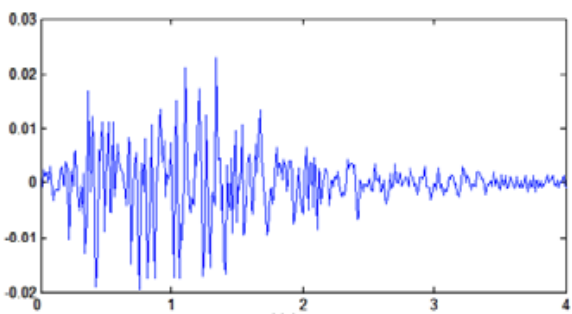

5) Acceleration Time History of A15 Measuring Point

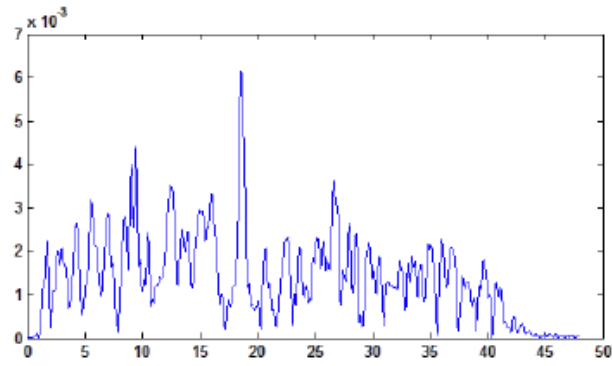

6) Frequency Spectra of A15 Measuring Point

Fig. (11). Comparison of lateral acceleration time histories and Fourier spectrum of soil.

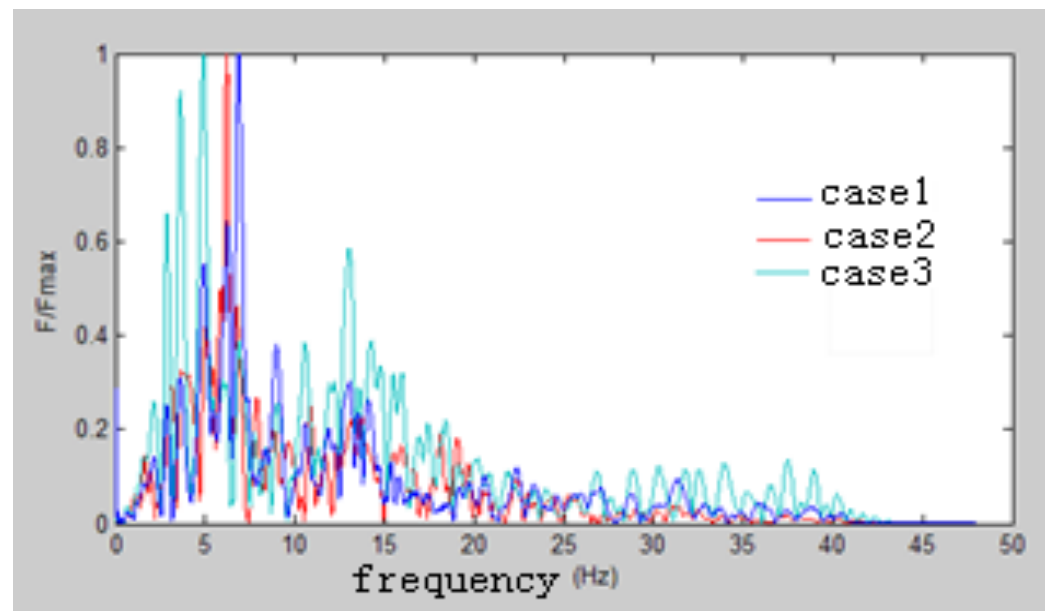

Fig. (12). Soil response frequency trait under different peak acceleration seismic wave.

peak acceleration, soil predominant frequency moved toward the left, and the seismic wave frequency component of soil grew. The phenomenon proved that with the increase of load times, the wave impedance and shear stiffness of the soil is constantly decreasing and so natural frequency of the soil is constantly decreasing while the degree of soil damage is constantly increasing. The nonlinear characteristics of soil is clearly illustrated in Fig. (12).

\subsection{Damping Effect Analysis of Damping Layer}

In this article, damping ratio is utilized to describe damping layer effect, which is defined in the following formula: damping ratio $=$ (reacting value of damping layer without damping layer - reacting value with damping layer)/reacting value of damping layer without damping layer. Tables 5 and $\mathbf{6}$ present the strain damping ratio of lining vault, sidewall and invert arch monitoring at cross sections $\mathrm{B}$ and $\mathrm{C}$ under test conditions and numerical calculations. 
Table 5. Absorption effect of damping layer under every test condition (Strain).

\begin{tabular}{|c|c|c|c|c|}
\hline Working condition code & Section position & $\begin{array}{l}\text { B section damping } \\
\text { layer }(\mu \mathbf{m})\end{array}$ & $\begin{array}{l}\text { C section damping } \\
\text { layer }(\mu \mathbf{m})\end{array}$ & Damping ratio \\
\hline S7 & \multirow{3}{*}{ vault } & 1.57 & 2.22 & $29.28 \%$ \\
\hline S14 & & 2.14 & 2.97 & $27.95 \%$ \\
\hline $\mathrm{S} 21$ & & 2.53 & 3.58 & $29.33 \%$ \\
\hline S14 & \multirow[t]{2}{*}{ sidewall } & 5.91 & 7.93 & $25.47 \%$ \\
\hline $\mathrm{S} 21$ & & 6.42 & 8.84 & $27.38 \%$ \\
\hline S7 & invert arch & 2.77 & 3.74 & $25.94 \%$ \\
\hline
\end{tabular}

Table 6. Absorption effect of damping layer under numerical calculation (Strain).

\begin{tabular}{|c|c|c|c|c|}
\hline Working condition code & Section position & Set aseismatic joint $(\mu \mathrm{m})$ & $\begin{array}{l}\text { No aseismatic } \\
\text { joint }(\mu \mathbf{m})\end{array}$ & Damping ratio \\
\hline S7 & \multirow{3}{*}{ vault } & 1.56 & 2.68 & $41.79 \%$ \\
\hline S14 & & 2.24 & 3.47 & $35.45 \%$ \\
\hline S21 & & 2.19 & 3.29 & $33.43 \%$ \\
\hline S14 & \multirow[t]{2}{*}{ sidewall } & 4.29 & 6.49 & $33.90 \%$ \\
\hline S21 & & 4.93 & 8.43 & $41.52 \%$ \\
\hline S7 & invert arch & 1.54 & 2.94 & $47.62 \%$ \\
\hline
\end{tabular}

Table 7. Absorption effect of damping layer under model test (Stress).

\begin{tabular}{|c|c|c|c|}
\hline \multirow{3}{*}{ Section position } & Damping layer & Largest hoop stress ( MPa) & Maximum longitudinal axial stress (Pa) \\
\hline \hline \multirow{3}{*}{ vault } & No damping layer & 2.78 & -2.62 \\
\cline { 2 - 4 } & set damping layer & 1.57 & -1.57 \\
\cline { 2 - 4 } & damping ratio & $43.53 \%$ & $40.08 \%$ \\
\hline \multirow{3}{*}{ sidewall } & No damping layer & 5.84 & 3.27 \\
\cline { 2 - 4 } & set damping layer & 4.01 & 2.55 \\
\cline { 2 - 4 } & damping ratio & $31.34 \%$ & $22.02 \%$ \\
\hline \multirow{2}{*}{ invert arch } & No damping layer & -1.92 & -0.45 \\
\cline { 2 - 4 } & set damping layer & -0.87 & -0.38 \\
\cline { 2 - 4 } & damping ratio & $54.69 \%$ & $15.56 \%$ \\
\hline
\end{tabular}


Table 8. Absorption effect of damping layer under numerical calculation (stress).

\begin{tabular}{|c|c|c|c|}
\hline \multirow{3}{*}{ Section position } & Damping layer & Largest hoop stress (MPa) & Maximum longitudinal axial stress (Pa) \\
\hline \hline \multirow{3}{*}{ vault } & No damping layer & 2.45 & -1.85 \\
\cline { 2 - 4 } & set damping layer & 1.23 & $31.89 \%$ \\
\cline { 2 - 4 } & damping ratio & $49.80 \%$ & 0.86 \\
\hline \multirow{3}{*}{ sidewall } & No damping layer & 4.22 & 0.57 \\
\cline { 2 - 4 } & set damping layer & 3.01 & $33.72 \%$ \\
\cline { 2 - 4 } & damping ratio & $28.67 \%$ & -0.36 \\
\hline \multirow{3}{*}{ invert arch } & No damping layer & -1.24 & -0.28 \\
\cline { 2 - 4 } & set damping layer & -0.63 & $22.22 \%$ \\
\cline { 2 - 4 } & damping ratio & $49.19 \%$ & \\
\hline
\end{tabular}

When the damping layer is placed at the tunnel entrance, under the seismic wave effect of exceeding probability of $10 \%, 5 \%$ and $2 \%$, the lining strain value of the test decreases by $30.86 \%$ on average, and lining strain value of FEM decreases by $41.68 \%$ on average (Comparing section B with damping layer to section $\mathrm{C}$ without damping layer).

Table 7 and Table 8 display the stress status of lining vault, sidewall and invert monitoring at cross section $B$ and $\mathrm{C}$ in test and calculation, respectively. Comparing Section B with damping layer to Section $\mathrm{C}$ without damping layer, under the seismic wave effect of exceeding probability of $10 \%$, $5 \%$ and $2 \%$, lining hoop stress value of test decreases by $43.18 \%$ on average, lining hoop stress value of FEM decreases by $42.55 \%$ on average and lining maximum axial stress value of test decreases by $25.88 \%$ on average, and lining maximum axial stress value of FEM decreases by $29.27 \%$ on average.

\section{CONCLUSION}

Using the entrance of the Galongla tunnel as the prototype, similar relationships to the model were drafted. Seismic resistance and damping model tests were composed of materials similar to the actual tunnel's surrounding rocks. The lining has seismic joints, damping layers, and measuring points on the shaking table model similar to those in the actual tunnel. Results of the shaking table tests and the calculations from numerical simulation analysis of the tunnel coincide closely with each other. Damping layer effects were analyzed under stress and strain tests and the following conclusions obtained:

(1) Resonance will not occur on the physical models during the experiment. Amplification effect of the surrounding rocks on the low frequency components remain below 20 $\mathrm{Hz}$, especially if the components are close to the dominant frequency of the soil and the filter effect on high frequency components beyond $20 \mathrm{~Hz}$ is noticeable.

(2) The acceleration amplification factor increases from the bottom to the top of the slope.

(3) Test model and finite element calculations are correct based on the approximate results of the test and finite elements.
(4) Setting damping layers would not change the characteristics of the spectrum of structural seismic response. An acceleration time history curve and Fourier spectrum of the lining are similar to those of the surrounding rocks and the predominant frequency of the lining is the same as surrounding rocks. The damping layers can however filter the high frequency range.

(5) Setting damping layers will increase the peak acceleration of the lining. The stress damping ratio of damping layers in the test is approximately $34.49 \%$, whereas the damping ratio of strain in the test is $30.86 \%$.

\section{CONFLICT OF INTEREST}

The authors confirm that this article content has no conflict of interest.

\section{ACKNOWLEDGEMENTS}

This work is supported by the National natrue Sciences Found, China (51078342).

\section{REFERENCES}

[1] T. Sun, B. Ga, and Z. Ye, "Discussion on anti-seismic and seismicrelieving measures and corresponging research methods for underground structures," Modem Tunnelling Technology, vol. 44, no. 3, pp. 1-5, 2007.

[2] L. Xiong, T. Li, and L. Yang, "Umerical analysis of two2shock absorption measures of tunnel," Hydrogeology and Engineering Geology, vol. 17, pp. 36-40, 2007

[3] F. Gao, Y. Shi, and S. Yan, "Study of two shock absorption measures in tunnel," Chinese Journal of Rock Mechanics and Engineering, vol. 24, no. 2, pp. 222-229, 2005.

[4] Y. Ling, and B. Gao, "Study on shock absorption measures for double-lane highway tunnels in high earthquake intensity regions," Tunnel Construction, vol. 28, no. 4, pp. 412-415, 2008.

[5] Z. Lin, S. Jiang, and H. Jiang, "Design of test plan for aseismic modei of large-size vibration table in highway tunnel," Technology of Highway and Transport, vol. 6, pp. 92-95, 2009.

[6] S. Jiang, H. Jiang, and X. Wang, "Analysis of seismic response in tunnel entrance of highway in seismic region with strong motion," HIGHWAY, vol. 2, pp. 194-198, 2009.

[7] M. Lou, W. Wang, and T. Zhu, "Soil lateral boundary effect in shaking table model test of soil-structure system," Earthquake Engineering and Engineering Vibration, vol. 20, no. 4, pp. 30-36, 2000 . 
[8] L. Yang, G. Wang, and Y. Zheng, "Shaking table test on metro station structure and $3 \mathrm{~d}$ numerical simulation of seismic response," Chinese Journal of Rock Mechanics and engineering, vol. 26, no. 8, pp. 1538-1545, 2007.

[9] Y. Li, T. Li, and D. Wang, "Large-scale shaking table test for vibration-absorption measures of portal section of huangcaoping Tunnel No.2," Chinese Journal of Rock Mechanics and Engineering, vol. 28, no. 6, pp. 1128-1136, 2009.
[10] M. Wang, and G. Cui, "Establishment of tunnel damping model and research on damping effect with model test in highly seismic area," Rock and Soil Mechanics, vol. 31, no. 6, pp. 1884-1890, 2010.

[11] L. Gao, and Y. Chen, "Analysis and shock absorption measures of tunnel based on ANSYS," Journal of Shihezi University (Natural Science), vol. 26, no. 4, pp. 495-498, 2008.

Received: February 03, 2015

Revised: April 03, 2015

Accepted: May 25, 2015

(C) Zheng and Jiang; Licensee Bentham Open.

This is an open access article licensed under the terms of the (https://creativecommons.org/licenses/by/4.0/legalcode), which permits unrestricted, noncommercial use, distribution and reproduction in any medium, provided the work is properly cited. 